\title{
ENSINO MÉDIO: POSSIBILIDADES DE AVALIAÇÃO
}

\author{
Carmen Sylvia Vidigal Moraes* \\ OCIMAR MunhOZ AlaVARSE**
}

\begin{abstract}
RESUMO: Neste artigo procura-se articular um conjunto de indicadores que permitiriam avaliar o ensino médio, incluindo a modalidade de educação de jovens e adultos. Parte-se de uma série histórica de matrículas no período de 1991 a 2010, com taxas líquidas de matrícula para a população de 15 a 17 anos, por dependências administrativas e turnos. Abarcam-se, também, as taxas de rendimento, especialmente as taxas de aprovação que expressam o sucesso no fluxo escolar. O quadro é completado com os resultados de desempenho no SAEB, que se conjugam com as taxas de aprovação para compor O IDEB, apresentado pelo MEC como indicador de qualidade da educação básica, o que remete a algumas problematizações sobre a concepção de avaliação e qualidade. Tais indicadores sinalizam os desafios de atendimento dessa etapa da educação básica às vésperas de sua obrigatoriedade, nos marcos do que se denomina democratização do ensino. Detalha-se o PRoEja no escopo de incluir outros elementos para uma avaliação mais abrangente do ensino médio, notadamente em relação à EJA e ao mundo do trabalho.
\end{abstract}

Palavras-chave: Ensino médio. Educação profissional. Educação de adultos. Avaliações nacionais.

\section{HigH SCHOOL: EVALUATION POSSIBILITIES}

ABSTRACT: This paper correlates a set of indicators to assess both high school and the Education Program for Youth and Adults. The first ones are the enrolment data from 1991 to 2010, with the net enrollment rates for the 15-17 year old students by administrative regions and shifts (morning, afternoon, and evening). It also considers yield rates, especially approval ones, which illustrate schooling success. This framework is completed by the performance results of the SAEв (Sistema de Avaliação da Educação Básica - Evaluation System of Basic Education), which are combined to the approval rates to compose the IDEB (Índice de Desenvolvimento da Educação Básica - Index of Basic Education Development). The latter is presented by the Ministry of Education (MEC) as an indicator of the quality of basic education, which raises some problematizations of the concepts of assessment and quality.

\footnotetext{
* Livre-docente e professora do Departamento de Administração Escolar e Economia da Educação, da Faculdade de Educação da Universidade de São Paulo (USP).E-mail: moraescs@usp.br

** Doutor em Educação e professor do Departamento de Administração Escolar e Economia da Educação, da Faculdade de Educação da Universidade de São Paulo (USP). E-mail: ocimar@usp.br
} 
These indicators highlight the challenges faced to satisfy the demands of this education stage, which should soon become compulsory, as part of the so called democratization of education. PROEJA is detailed to include other elements for a more comprehensive assessment of high school, especially with regard to adult education and the world of work.

Key words: High school. Professional education. Adult education. National assessments.

\section{LYCÉE: POSSIBILITÉS D'ÉVALUATION}

RÉSUMÉ: Cet article cherche à articuler un ensemble d'indicateurs permettant d'évaluer le lycée, y compris le Programme d'éducation pour jeunes et adultes. Les premiers sont les données concernant les inscriptions entre 1991 et 2010, avec les taux d'inscription nets pour les élèves de 15 à 17 ans, par région administrative et période (matin ou après-midi). Les taux de rendement, spécialement ceux d'approbation, qui expriment le succès au long de la scolarisation, sont également pris en compte. Ce cadre est complété par les résultats de performance du saeb (Sistema de Avaliação da Educação Básica - Système d'évaluation de l'enseignement de base), qui se conjuguent aux taux d'approbation pour composer L'IDeb (Índice de Desenvolvimento da Educação Básica - Indice de développement de l'éducation de base) présenté par le m.E.c. (Ministère de l'éducation et de la Culture) comme indicateur de qualité de l'éducation de base, ce qui renvoie à certaines problématisations de la conception d'évaluation et de qualité. Ces indicateurs signalent les défis pour répondre à cette étape de l'éducation de base, sous le coup de devenir obligatoire, dans le cadre de ce que l'on appelle la démocratisation de l'enseignement. Nous détaillons le Proeja ajouter certains éléments permettant une évaluation plus vaste du lycée, notamment pour ce qui est de l'EJA (Educação para jovens e adultos - Éducation pour les jeunes et les adultes) et du monde du travail.

Mots-clés: Lycée. Éducation professionnelle. Éducation des adultes. Évaluations nationales.

\section{Introdução}

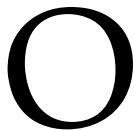

ensino médio, etapa da educação básica que, de acordo com a Emenda Constitucional (EC) n. 59/2009, será obrigatória em 2016, tem sido objeto de um amplo conjunto de trabalhos, os quais revelam, nas várias vertentes, toda a sua complexidade social, política e pedagógica.

É objetivo deste artigo empreender uma avaliação do ensino médio, incluindo a modalidade de educação de jovens e adultos (EJA), recuperando dados e aspectos que podem se constituir em pontos de apoio para o exame de sua relação com os processos de democratização da escola. Procura-se sublinhar como o ensino médio integrado à educação profissional, em particular o Programa Nacional de Integração da Educação Profissional com a Educação Básica na Modalidade de Educação de Jovens e Adultos (PROEJA) (Brasil, 2006), constitui iniciativa de política pública que, 
por suas características e finalidades, pode indicar caminhos para a democratização e a qualidade do ensino médio. Não se trata, aqui, de apontar a decantada "crise" do ensino médio, mas de realçar essa etapa educacional como uma arena, por excelência, na qual projetos de políticas sociais - com seus fundamentos e concepções - disputam proeminência.

Em relação aos indicadores sobre o ensino médio, retomamos clássicas estatísticas que, tendo o Brasil como pano de fundo, sublinham aspectos que, por um lado, não foram superados e, por outro, incorporam tendências do que vem se denominando avaliação da qualidade do ensino, salientadas nas políticas educacionais mais recentes. A partir de 1995, com a divulgação dos resultados do Sistema de Avaliação da Educação Básica (sАeb) e do Exame Nacional do Ensino Médio (ENEM), em 1998, o ensino médio passa a ser avaliado, também, em função do desempenho de seus alunos. Tal perspectiva acentua-se quando da criação, em 2007, do Índice de Desenvolvimento da Educação Básica (IDEB) e da divulgação dos resultados do ENEM por escola, desde 2005, consolidada pela edição do Plano de Desenvolvimento da Educação (PDE), em 2008.

\section{O ensino médio no Censo Escolar}

Com base nos dados do Censo Escolar, disponibilizados pelo Instituto Nacional de Estudos e Pesquisas Educacionais Anísio Teixeira (INEP) nas Sinopses Estatísticas da Educação Básica, consideramos que um passo incontornável para a avaliação do ensino médio está em situar seu atendimento, cujo número de matrículas engloba os alunos que o fazem na forma integrada à educação profissional e os que cursam o Normal/Magistério. No caso da educação profissional, além daquela que se realiza de forma integrada ao ensino médio, também existem outras duas possibilidades: a concomitante, na qual o aluno cursou o ensino médio na mesma instituição ou em unidades distintas - portanto com outra matrícula -, e a subsequente, destinada a aluno que concluiu o ensino médio, como foi definido pela Lei n. 11.741, de 2008.

Na tabela a seguir, nas matrículas de 1991 a 2010, podem ser identificados dois movimentos. O primeiro, caracterizado por forte expansão entre 1991 e 2004 - de 3.772.698 para 9.169 .357 de matrículas -, com uma variação de $143 \%$, seguidos por uma queda de $9 \%$ até 2007 e por um patamar de estabilização, nos três últimos anos, com 8.357.675 de matrículas em 2010. Nesse período, a taxa líquida de matrícula para a população de 15 a 17 anos, utilizando-se dados da Pesquisa Nacional por Amostra de Domicílios (PNAD), do Instituto Brasileiro de Geografia e Estatística (IBGE), passa de 17,3\%, em 1991, para 32,7\%, em 1999, atingindo 44,2\% em 2004 e 50,9\% em 2009 (IBGE, 2010). Apesar da variação positiva, configura-se ainda a incompletude do processo de democratização da escola, pois a "outra metade" da 
juventude ou permanece no ensino fundamental (34,3\%), fruto de reprovações ou ingresso tardio, ou está sem frequentar qualquer escola $(14,8 \%)$.

\section{Tabela 1}

Ensino médio. Matrículas por dependência administrativa: Brasil (1991 a 2010)

\begin{tabular}{|c|c|c|c|c|c|c|c|c|c|}
\hline \multirow{2}{*}{ Ano } & \multirow{2}{*}{$\begin{array}{l}\text { Total de } \\
\text { matrículas }\end{array}$} & \multicolumn{2}{|c|}{ Federal } & \multicolumn{2}{|c|}{ Estadual } & \multicolumn{2}{|c|}{ Municipal } & \multicolumn{2}{|c|}{ Privada } \\
\hline & & № & $\%$ & № & $\%$ & № & $\%$ & № & $\%$ \\
\hline 1991 & 3.772 .698 & 103.146 & $2,7 \%$ & 2.472 .910 & $65,5 \%$ & 177.268 & $4,7 \%$ & 1.019 .374 & $27,0 \%$ \\
\hline 1992 & 4.104 .643 & 98.584 & $2,4 \%$ & 2.836 .676 & $69,1 \%$ & 223.855 & $5,5 \%$ & 945.528 & $23,0 \%$ \\
\hline 1993 & 4.478 .631 & 93.918 & $2,1 \%$ & 3.180 .546 & $71,0 \%$ & 244.397 & $5,5 \%$ & 959.770 & $21,4 \%$ \\
\hline 1994 & 4.932 .552 & 100.007 & $2,0 \%$ & 3.522 .970 & $71,4 \%$ & 267.803 & $5,4 \%$ & 1.041 .772 & $21,1 \%$ \\
\hline 1995 & 5.374 .831 & 113.312 & $2,1 \%$ & 3.808 .326 & $70,9 \%$ & 288.708 & $5,4 \%$ & 1.164 .485 & $21,7 \%$ \\
\hline 1996 & 5.739 .077 & 113.091 & $2,0 \%$ & 4.137.324 & $72,1 \%$ & 312.143 & $5,4 \%$ & 1.176 .519 & $20,5 \%$ \\
\hline 1997 & 6.405 .057 & 131.278 & $2,0 \%$ & 4.644 .671 & $72,5 \%$ & 362.043 & $5,7 \%$ & 1.267 .065 & $19,8 \%$ \\
\hline 1998 & 6.968 .531 & 122.927 & $1,8 \%$ & 5.301 .475 & $76,1 \%$ & 317.488 & $4,6 \%$ & 1.226 .641 & $17,6 \%$ \\
\hline 1999 & 7.769 .199 & 121.673 & $1,6 \%$ & 6.141 .907 & $79,1 \%$ & 281.255 & $3,6 \%$ & 1.224 .364 & $15,8 \%$ \\
\hline 2000 & 8.192 .948 & 112.343 & $1,4 \%$ & 6.662 .727 & $81,3 \%$ & 264.459 & $3,2 \%$ & 1.153 .419 & $14,1 \%$ \\
\hline 2001 & 8.398 .008 & 88.537 & $1,1 \%$ & 6.962 .330 & $82,9 \%$ & 232.661 & $2,8 \%$ & 1.114 .480 & $13,3 \%$ \\
\hline 2002 & 8.710 .584 & 79.974 & $0,9 \%$ & 7.297.179 & $83,8 \%$ & 210.631 & $2,4 \%$ & 1.122 .900 & $12,9 \%$ \\
\hline 2003 & 9.072 .942 & 74.344 & $0,8 \%$ & 7.667 .713 & $84,5 \%$ & 203.368 & $2,2 \%$ & 1.127 .517 & $12,4 \%$ \\
\hline 2004 & 9.169 .357 & 67.652 & $0,7 \%$ & 7.800 .983 & $85,1 \%$ & 189.331 & $2,1 \%$ & 1.111 .391 & $12,1 \%$ \\
\hline 2005 & 9.031 .302 & 68.651 & $0,8 \%$ & 7.682 .995 & $85,1 \%$ & 182.067 & $2,0 \%$ & 1.097 .589 & $12,2 \%$ \\
\hline 2006 & 8.906 .820 & 67.650 & $0,8 \%$ & 7.584 .391 & $85,2 \%$ & 186.045 & $2,1 \%$ & 1.068 .734 & $12,0 \%$ \\
\hline 2007 & 8.369 .369 & 68.999 & $0,8 \%$ & 7.239 .523 & $86,5 \%$ & 163.779 & $2,0 \%$ & 897.068 & $10,7 \%$ \\
\hline 2008 & 8.366 .100 & 82.033 & $1,0 \%$ & 7.177.377 & $85,8 \%$ & 136.167 & $1,6 \%$ & 970.523 & $11,6 \%$ \\
\hline 2009 & 8.337 .160 & 90.353 & $1,1 \%$ & 7.163 .020 & $85,9 \%$ & 110.780 & $1,3 \%$ & 973.007 & $11,7 \%$ \\
\hline 2010 & 8.357 .675 & 101.715 & $1,2 \%$ & 7.177.019 & $85,9 \%$ & 91.103 & $1,1 \%$ & 987.838 & $11,8 \%$ \\
\hline
\end{tabular}

Fonte: MEC/INEP.

O segundo movimento, relativo às matrículas por dependência administrativa, revela, de imediato, a consolidação da escola pública e a redução da participação das escolas privadas na oferta de matrículas, que decresce de $27 \%$, em 1991, para 11,8\%, em 2010. Ao longo dos 19 anos da série histórica, as matrículas por escolas 
privadas, municipais e federais mantêm-se praticamente constantes. No âmbito das escolas públicas, a ampliação do atendimento deu-se, nas últimas décadas, pela crescente participação das escolas estaduais, que passam a se responsabilizar por $65,5 \%$, em 1991, e 85,9\%, em 2010, do total das matrículas, e por 97,4\% das matrículas de escolas públicas.

Destaca-se, com referência aos dados de 2010, que 215.533 matrículas são relativas ao ensino médio integrado à educação profissional de nível médio, o que corresponde a $2,6 \%$ do total de matrículas.

Com relação às matrículas por turno, conforme a próxima tabela, desde 1995 constata-se um movimento contínuo de crescimento do percentual de matrículas no diurno, que passa de $41,3 \%$ para $65,3 \%$ em 2010 . Contudo, quando notamos a distribuição das matrículas nos turnos pelas dependências administrativas, tem-se que nas escolas privadas o diurno concentra, em 2010,96,6\% das matrículas. Nas escolas estaduais este movimento é retardado, sendo que em 2010 o percentual atinge 60,8\% das matrículas.

\section{Tabela 2}

Ensino médio. Percentual de matrículas no diurno por dependência administrativa: Brasil (1991 a 2009)

\begin{tabular}{|l|l|l|l|l|l|}
\hline Ano & Total & Federal & Estadual & Municipal & Privada \\
\hline $\mathbf{1 9 9 1}$ & $41,7 \%$ & $70,1 \%$ & $34,6 \%$ & $23,0 \%$ & $59,2 \%$ \\
\hline $\mathbf{1 9 9 2}$ & $45,7 \%$ & $73,7 \%$ & $38,6 \%$ & $33,8 \%$ & $67,1 \%$ \\
\hline $\mathbf{1 9 9 3}$ & $52,0 \%$ & $74,4 \%$ & $47,5 \%$ & $30,0 \%$ & $70,6 \%$ \\
\hline $\mathbf{1 9 9 4}$ & $54,1 \%$ & $76,1 \%$ & $49,6 \%$ & $35,6 \%$ & $72,1 \%$ \\
\hline $\mathbf{1 9 9 5}$ & $41,3 \%$ & $74,3 \%$ & $33,4 \%$ & $24,4 \%$ & $67,9 \%$ \\
\hline $\mathbf{1 9 9 6}$ & $43,9 \%$ & $76,3 \%$ & $36,3 \%$ & $26,6 \%$ & $72,1 \%$ \\
\hline $\mathbf{1 9 9 7}$ & $44,1 \%$ & $74,8 \%$ & $36,6 \%$ & $26,1 \%$ & $73,4 \%$ \\
\hline $\mathbf{1 9 9 8}$ & $45,2 \%$ & $79,0 \%$ & $38,1 \%$ & $26,7 \%$ & $77,4 \%$ \\
\hline $\mathbf{1 9 9 9}$ & $45,5 \%$ & $79,5 \%$ & $39,0 \%$ & $28,3 \%$ & $78,5 \%$ \\
\hline $\mathbf{2 0 0 0}$ & $46,6 \%$ & $82,5 \%$ & $40,5 \%$ & $30,4 \%$ & $82,5 \%$ \\
\hline $\mathbf{2 0 0 1}$ & $48,7 \%$ & $88,0 \%$ & $42,7 \%$ & $33,4 \%$ & $86,5 \%$ \\
\hline $\mathbf{2 0 0 2}$ & $51,1 \%$ & $90,8 \%$ & $45,3 \%$ & $36,1 \%$ & $89,3 \%$ \\
\hline $\mathbf{2 0 0 3}$ & $53,1 \%$ & $94,3 \%$ & $47,5 \%$ & $35,8 \%$ & $91,1 \%$ \\
\hline $\mathbf{2 0 0 4}$ & $54,9 \%$ & $96,6 \%$ & $49,6 \%$ & $36,6 \%$ & $92,7 \%$ \\
\hline $\mathbf{2 0 0 5}$ & $55,9 \%$ & $96,5 \%$ & $50,7 \%$ & $36,1 \%$ & $93,2 \%$ \\
\hline
\end{tabular}




\begin{tabular}{|l|l|l|l|l|l|}
\hline $\mathbf{2 0 0 6}$ & $57,2 \%$ & $96,8 \%$ & $52,2 \%$ & $36,3 \%$ & $93,5 \%$ \\
\hline $\mathbf{2 0 0 7}$ & $58,8 \%$ & $97,5 \%$ & $54,3 \%$ & $41,4 \%$ & $95,1 \%$ \\
\hline $\mathbf{2 0 0 8}$ & $60,9 \%$ & $96,7 \%$ & $56,1 \%$ & $43,2 \%$ & $95,8 \%$ \\
\hline $\mathbf{2 0 0 9}$ & $63,0 \%$ & $97,6 \%$ & $58,3 \%$ & $71,5 \%$ & $96,0 \%$ \\
\hline $\mathbf{2 0 1 0}$ & $65,3 \%$ & $96,7 \%$ & $60,8 \%$ & $64,6 \%$ & $96,6 \%$ \\
\hline
\end{tabular}

Fonte: MEC/INEP.

Conforme os dados apresentados na Tabela 3, cuja série histórica foi definida em função da disponibilidade de informações para matrículas presenciais e semipresenciais em EJA nas Sinopses disponibilizadas pelo INEP, nota-se uma queda nas matrículas, de 1.750.662, em 2006, para 1.388.852, em 2010. Na apresentação da Sinopse Estatística da Educação Básica de 2007 encontramos a informação de que a queda no ano de 2007, em relação a 2006, deve-se ao refinamento na coleta de dados, que antes computava alunos em cursos organizados em módulos, o que permitia que um mesmo aluno pudesse ter mais de uma matrícula, sem, contudo, mencionar o impacto percentual dessa alteração no processamento dos dados.

\section{Tabela 3}

Matrículas no ensino médio EJA por dependência administrativa: Brasil (2002 a 2010)

\begin{tabular}{|c|c|c:c|c:c|}
\hline \multirow{2}{*}{ Ano } & Total & \multicolumn{2}{|c|}{ Pública } & \multicolumn{2}{c|}{ Privada } \\
\cline { 2 - 6 } & $\mathbf{N}^{\mathbf{0}}$ & $\mathbf{N}^{\mathbf{0}}$ & $\mathbf{\%}$ & $\mathbf{N}^{\mathbf{o}}$ & $\%$ \\
\hline $\mathbf{2 0 0 2}$ & 1.287 .555 & 1.037 .122 & $80,5 \%$ & 250.433 & $19,5 \%$ \\
\hline $\mathbf{2 0 0 3}$ & 1.452 .430 & 1.227 .338 & $84,5 \%$ & 225.092 & $15,5 \%$ \\
\hline $\mathbf{2 0 0 4}$ & 1.709 .053 & 1.504 .045 & $88,0 \%$ & 205.008 & $12,0 \%$ \\
\hline $\mathbf{2 0 0 5}$ & 1.717 .592 & 1.546 .464 & $90,0 \%$ & 171.128 & $10,0 \%$ \\
\hline $\mathbf{2 0 0 6}$ & 1.750 .662 & 1.606 .394 & $91,8 \%$ & 144.268 & $8,2 \%$ \\
\hline $\mathbf{2 0 0 7}$ & 1.608 .559 & 1.517 .168 & $94,3 \%$ & 91.391 & $5,7 \%$ \\
\hline $\mathbf{2 0 0 8}$ & 1.635 .245 & 1.531 .712 & $93,7 \%$ & 103.533 & $6,3 \%$ \\
\hline $\mathbf{2 0 0 9}$ & 1.547 .275 & 1.447 .029 & $93,5 \%$ & 100.246 & $6,5 \%$ \\
\hline $\mathbf{2 0 1 0}$ & 1.388 .852 & 1.298 .577 & $93,5 \%$ & 90.275 & $6,5 \%$ \\
\hline
\end{tabular}

Fonte: MEC/INEP.

Esse quadro reforça a hipótese de a EJA ainda não estar sendo efetivamente incorporada às políticas educacionais. A queda no atendimento, em números absolutos e, proporcionalmente, no noturno do ensino médio considerado "regular", tem 
gerado, objetivamente, vagas que não são disponibilizadas à EJA. Para corroborar esta hipótese, temos a situação no estado de São Paulo, onde particularmente a rede estadual tem restringido a oferta de vagas de EJA nos anos finais do ensino fundamental e no ensino médio, como se vislumbra pelas denúncias, inclusive jurídicas, de movimentos organizados em torno da EJA, como o Fórum Estadual de Educação de Jovens e Adultos de São Paulo (2010).

Pela análise da Tabela 3, depreende-se que o ensino médio na Eja configurou um processo de alta concentração das matrículas em escolas públicas, pois as escolas privadas reduziram suas matrículas em $63 \%$ no período de 9 anos. Isto acentua o desafio de escolarização de amplas parcelas da população para as políticas públicas de educação.

Com respeito ao ensino médio na modalidade eja, tem-se um quadro de atendimento muito reduzido, sobretudo ao se levar em conta a demanda potencial existente no Brasil. Consultando os dados da PNAD 2009 (IBGE, 2010), pode-se dimensionar essa demanda em 81,3 milhões de matrículas, pois na população de 18 a 24 anos de idade, estimada em 23 milhões de pessoas, $47 \%$ têm menos de 11 anos de estudo, correspondendo a 10,8 milhões, e na população com 25 ou mais anos de idade, estimada em 112 milhões de pessoas, 63\% têm menos de 11 anos de estudo, correspondendo a 70,4 milhões. Deve-se observar, ainda, que nesse contingente de 81,3 milhões de pessoas incluem-se desde aquelas que nunca foram à escola até as que já chegaram a cursar algumas séries do ensino médio.

No caso das matrículas da EjA integrada à educação profissional, disponibilizadas nas Sinopses Estatísticas desde 2007, destaca-se a participação da dependência administrativa federal, em contraste com o conjunto do ensino médio, como se vê na Tabela 4, embora no último levantamento as redes estaduais tenham aumentado significativamente sua oferta. Contudo, trata-se de um fenômeno, do ponto de vista quantitativo, muito restrito, pois essas matrículas, apesar do crescimento em torno de $290 \%$ no período retratado, representam apenas 3\% do total de matrículas do ensino médio Eja. Relativamente a esse quesito, encontra-se no Projeto de Lei do Plano Nacional de Educação (PNE) 2011-2020 enviado ao Congresso Nacional, em sua Meta 10, a proposta de oferecer, no mínimo, $25 \%$ das matrículas de EjA na forma integrada à educação profissional, o que, se aprovada, implicará a necessidade de mobilização de grandes recursos diante da diferença a ser superada.

\section{0 rendimento do ensino médio}

Outro aspecto a ser considerado na apreensão do ensino médio diz respeito às taxas de rendimento, constituídas pelas taxas de aprovação, reprovação e abandono, 
que são apuradas ao final de cada período letivo. Em função do peso que as escolas estaduais possuem no atendimento do ensino médio, optamos por contrastar suas taxas com as das escolas privadas.

\section{Tabela 4}

Matrículas. Ensino médio na EJA integrada à educação profissional: Brasil (2007 a 2010)

\begin{tabular}{|c|c|c|c|c|c|c|c|c|c|}
\hline \multirow{2}{*}{ Ano } & \multicolumn{2}{|c|}{ Federal } & \multicolumn{2}{|c|}{ Estadual } & \multicolumn{2}{c|}{ Municipal } & \multicolumn{2}{c|}{ Privada } & \multirow{2}{*}{ Total } \\
\cline { 2 - 10 } & № & $\mathbf{\%}$ & № & $\mathbf{\%}$ & $\mathbf{N}^{\mathbf{o}}$ & $\mathbf{\%}$ & № & $\mathbf{\%}$ & \\
\hline $\mathbf{2 0 0 7}$ & 4.772 & $49,0 \%$ & 1.229 & $12,6 \%$ & 131 & $1,3 \%$ & 3.615 & $37,1 \%$ & $\mathbf{9 . 7 4 7}$ \\
\hline $\mathbf{2 0 0 8}$ & 8.014 & $53,6 \%$ & 3.958 & $26,5 \%$ & 28 & $0,2 \%$ & 2.939 & $19,7 \%$ & $\mathbf{1 4 . 9 3 9}$ \\
\hline $\mathbf{2 0 0 9}$ & 10.883 & $55,7 \%$ & 4.327 & $22,2 \%$ & 66 & $0,3 \%$ & 4.257 & $21,8 \%$ & $\mathbf{1 9 . 5 3 3}$ \\
\hline $\mathbf{2 0 1 0}$ & 14.078 & $36,9 \%$ & 19.919 & $52,2 \%$ & 40 & $0,1 \%$ & 4.115 & $10,8 \%$ & $\mathbf{3 8 . 1 5 2}$ \\
\hline
\end{tabular}

Fonte: MEC/INEP.

Conforme os dados da Tabela 5, no tocante à aprovação, persiste nas escolas estaduais uma situação na qual, praticamente, de cada quatro alunos matriculados, um não tem sucesso em ser aprovado para a série seguinte - ou para concluir o ensino médio -, ao passo que, nas escolas privadas, tal sucesso é mais elevado, embora não seja desprezível a perda nessa dependência administrativa.

\section{Tabela 5}

Ensino médio. Taxas de rendimento. Escolas estaduais e privadas: Brasil (1997 a 2010)

\begin{tabular}{|c|c:c|c|c|c|c|}
\hline \multirow{2}{*}{ Ano } & \multicolumn{3}{|c|}{ Estadual } & \multicolumn{3}{c|}{ Privada } \\
\cline { 2 - 7 } & Aprovação & Reprovação & Abandono & Aprovação & Reprovação & Abandono \\
\hline $\mathbf{1 9 9 7}$ & $77,6 \%$ & $7,8 \%$ & $14,7 \%$ & $88,6 \%$ & $6,5 \%$ & $4,9 \%$ \\
\hline $\mathbf{1 9 9 9}$ & $73,7 \%$ & $7,6 \%$ & $18,7 \%$ & $90,1 \%$ & $5,5 \%$ & $4,4 \%$ \\
\hline $\mathbf{2 0 0 1}$ & $74,5 \%$ & $8,5 \%$ & $17,0 \%$ & $92,0 \%$ & $5,1 \%$ & $2,9 \%$ \\
\hline $\mathbf{2 0 0 3}$ & $72,3 \%$ & $10,9 \%$ & $16,8 \%$ & $92,8 \%$ & $5,3 \%$ & $1,9 \%$ \\
\hline $\mathbf{2 0 0 5}$ & $70,5 \%$ & $12,3 \%$ & $17,2 \%$ & $92,7 \%$ & $5,8 \%$ & $1,5 \%$ \\
\hline $\mathbf{2 0 0 7}$ & $71,6 \%$ & $13,6 \%$ & $14,8 \%$ & $93,8 \%$ & $5,6 \%$ & $0,6 \%$ \\
\hline $\mathbf{2 0 0 9}$ & $73,5 \%$ & $13,5 \%$ & $13,0 \%$ & $93,3 \%$ & $6,2 \%$ & $0,5 \%$ \\
\hline $\mathbf{2 0 1 0}$ & $74,9 \%$ & $13,4 \%$ & $11,7 \%$ & $93,6 \%$ & $5,9 \%$ & $0,5 \%$ \\
\hline
\end{tabular}

Fonte: MEC/INEP. 
Quanto às taxas de reprovação e abandono, temos nas escolas estaduais quase que os mesmos patamares para ambas e, nas particulares, uma concentração de insucesso nas reprovações. Chama a atenção nas escolas estaduais o fato de que, ao aumento de matrículas, corresponde um aumento nas taxas de reprovação e a estabilidade nas taxas de abandono, indicando o desafio, já clássico, no sentido do desenvolvimento de políticas para a fixação dessa parcela da juventude que se aproxima da escola.

Na Tabela 6, o número de concluintes no ensino médio brasileiro expressa, por outros dados, as consequências das taxas de rendimento, pois, salvo um crescimento de concluintes entre 1997 e 1999, houve a estabilização no patamar de 1,8 milhões de concluintes a despeito dos incrementos nas matrículas, como destacado na análise da Tabela 1. Na coluna Proporção, numa situação sem perdas por reprovação e por abandono, a taxa de concluintes seria de $33 \%$, pois os alunos da $3^{\underline{a}}$ série, de cada ano, estariam concluindo essa etapa de ensino. Contudo, identifica-se um quadro muito distinto, visto que o patamar de concluintes se estabilizou em torno de $21,5 \%$, como mais um indício do fluxo com muitas perdas, por evasão e repetência, nas três séries do ensino médio.

\section{Tabela 6}

Números de concluintes no ensino médio: Brasil (1997 a 2010)

\begin{tabular}{|c|c|c|c|}
\hline Ano & Matrículas & Concluintes & Proporção \\
\hline $\mathbf{1 9 9 7}$ & 6.405 .057 & 1.330 .150 & $20,8 \%$ \\
\hline $\mathbf{1 9 9 8}$ & 6.968 .531 & 1.535 .943 & $22,0 \%$ \\
\hline $\mathbf{1 9 9 9}$ & 7.769 .199 & 1.786 .827 & $23,0 \%$ \\
\hline $\mathbf{2 0 0 0}$ & 8.192 .948 & 1.836 .130 & $22,4 \%$ \\
\hline $\mathbf{2 0 0 1}$ & 8.398 .008 & 1.855 .419 & $22,1 \%$ \\
\hline $\mathbf{2 0 0 2}$ & 8.710 .584 & 1.884 .874 & $21,6 \%$ \\
\hline $\mathbf{2 0 0 3}$ & 9.072 .942 & 1.851 .834 & $20,4 \%$ \\
\hline $\mathbf{2 0 0 4}$ & 9.169 .357 & 1.879 .044 & $20,5 \%$ \\
\hline $\mathbf{2 0 0 5}$ & 9.031 .302 & 1.858 .615 & $20,6 \%$ \\
\hline $\mathbf{2 0 0 6}$ & 8.906 .820 & 1.804 .173 & $20,3 \%$ \\
\hline $\mathbf{2 0 0 7}$ & 8.369 .369 & 1.749 .731 & $20,9 \%$ \\
\hline $\mathbf{2 0 0 8}$ & 8.366 .100 & 1.761 .425 & $21,1 \%$ \\
\hline $\mathbf{2 0 0 9}$ & 8.337 .160 & 1.797 .434 & $21,6 \%$ \\
\hline $\mathbf{2 0 1 0}$ & 8.357 .675 & 1.793 .167 & $21,5 \%$ \\
\hline
\end{tabular}

Fonte: MEC/INEP. 


\section{Avaliações externas como indicadores do processo de escolarização}

A partir do final dos anos de 1980, repercutindo um movimento existente, especialmente nos Estados Unidos da América e em alguns países da Europa, a educação básica brasileira passa a ser objeto de avaliações externas, inicialmente apresentadas como necessárias para o monitoramento do desempenho de seus estudantes em provas padronizadas, passíveis de permitir comparações entre redes e escolas. Esse quadro avaliativo ganhou densidade com a criação do sAEB no início dos anos de 1990, fruto de algumas iniciativas de avaliação patrocinadas pelo mEc. Tratava-se de inovação introduzida antes que se consolidasse um sistema de coletas de estatísticas referentes ao próprio funcionamento das escolas, num país que somente no início desse período começava a sinalizar horizontes de democratização da escola básica, o então ensino de primeiro grau.

As avaliações externas, apesar de se constituírem num dos traços do conjunto das reformas educacionais implementadas desde a década de 1980, foram marcadas, também, por vicissitudes, por conta de diferenças de objetivos e papéis no contexto dessas reformas, bem como por resistências a esse tipo de avaliação, como salientam Bonamino e Franco (1999). Ainda, é importante registrar, conforme os aportes de Sousa e Oliveira (2010, p. 796), que a "discussão da avaliação de sistemas abrange um amplo leque de questões de natureza técnica e, para além delas, implicações de ordem política, pois que está intimamente vinculada às políticas públicas de educação".

A presença das avaliações externas ganhou proeminência após o desdobramento, em 2005, do SAEB em duas avaliações complementares: a Avaliação Nacional do Rendimento Escolar (AnResc) - mais conhecida pelo nome de Prova Brasil - e a Avaliação Nacional da Educação Básica (ANEB). Ambas tendo como objeto a avaliação de língua portuguesa (leitura) e matemática (resolução de problemas), mediante provas com itens de múltipla escolha aplicadas em alunos de $4^{\mathrm{a}}$ e $8^{\underline{a}}$ séries do ensino fundamental e $3^{\mathrm{a}}$ série do ensino médio.

Adicionalmente aos resultados dessas avaliações, foram incorporadas as taxas de aprovação para o cálculo do IDEB, estimulando ações similares em várias redes públicas de ensino, com destaque para o Índice de Desenvolvimento da Educação no Estado de São Paulo (IDESP).

O IDEB surge oficialmente com o Plano de Metas Compromisso Todos pela Educação, por meio do Decreto n. 6.074, de 24 de abril de 2007. A sua fundamentação foi apresentada por Reynaldo Fernandes (2007), à época presidente do INEP, tendo sido enfatizado como um dos aspectos mais relevantes do Plano de Desenvolvimento da Educação (PDE) por Fernando Haddad (2008), ministro da Educação, apreciação corroborada por Saviani (2007) e por Weber (2008). Como indicador, o IDEB combina os resultados de desempenho nas provas do SAEB com taxas de aprovação de cada uma 
das unidades - escolas e redes - para as quais é calculado. Para as escolas públicas, com pelo menos 20 alunos nas $4^{\mathrm{a}} \mathrm{e} 8^{\mathrm{a}}$ séries do ensino fundamental, são utilizados os resultados da Prova Brasil; para todo o ensino médio - público e privado - e escolas privadas de ensino fundamental são utilizados os resultados da ANEB, cuja prova é semelhante, quanto ao conteúdo, à Prova Brasil, porém aplicada para uma amostra de alunos, como se fazia no SAEB até 2003. Todo esse processo é de responsabilidade do INEP.

O SAeв proporciona um olhar longitudinal sobre o ensino médio, desde 1995, com resultados bienais expressos na chamada Escala saeb. Para uma análise de seus resultados, em matemática e língua portuguesa nas escolas estaduais e privadas de ensino médio, temos os gráficos 1 e 2, nos quais estão as proficiências médias dos alunos que fizeram as provas das amostras de cada estrato.

Apesar das dificuldades e algumas controvérsias em torno de pontos-corte, entende-se que são essenciais para que se possa de fato estabelecer uma avaliação. Assim, considera-se na Escala SAEB um ponto abaixo do qual não deveria haver nenhum aluno, denominando-o de básico. Para matemática, o corte para o básico é de 275 e, com efeito, o que temos é que os resultados dos alunos de escolas estaduais, desde 1995, estão abaixo do básico. Os dos alunos de escolas privadas, apenas $12 \%$ do alunado do ensino médio, declinam a partir de 2003 e os dos alunos de escolas estaduais iniciam um processo de crescimento em 2005, diminuindo a diferença entre eles.

Em língua portuguesa, com o básico definido em 250, os alunos de escolas estaduais ficam um pouco acima do básico e apresentam um movimento de crescimento a partir de 2005, o que reduz a diferença entre eles, pois os alunos de escolas privadas praticamente estabilizaram o desempenho a partir desse momento.

Se os resultados são extremamente preocupantes pelo fato de a leitura e a resolução de problemas constituírem-se em domínios de base para o conjunto das atividades escolares, com profundas conexões com todas as disciplinas do ensino médio, ao mesmo tempo, isso não elimina a necessidade de que outros componentes curriculares sejam contemplados no SAEB. Além do que, a EJA nunca mereceu tratamento diferenciado em todo o ciclo de aplicação do SAEB.

Tem-se, ainda, como um obstáculo no sentido da incorporação mais efetiva dos resultados, que as matrizes de avaliação do SAEB - expressas em descritores -, denominadas de habilidades e competências por descreverem do ponto de vista cognitivo as capacidades pedagógicas, não são de domínio dos professores. Ou porque eles não as conhecem, apesar das campanhas de difusão que o MEC tem patrocinado, ou, principalmente, porque esse tipo de organização de provas e avaliações é raramente apresentado nos cursos de licenciatura. 


\section{Gráfico 1}

SAEB. Matemática. Ensino médio - Escolas estaduais e privadas: Brasil (1995-2009)

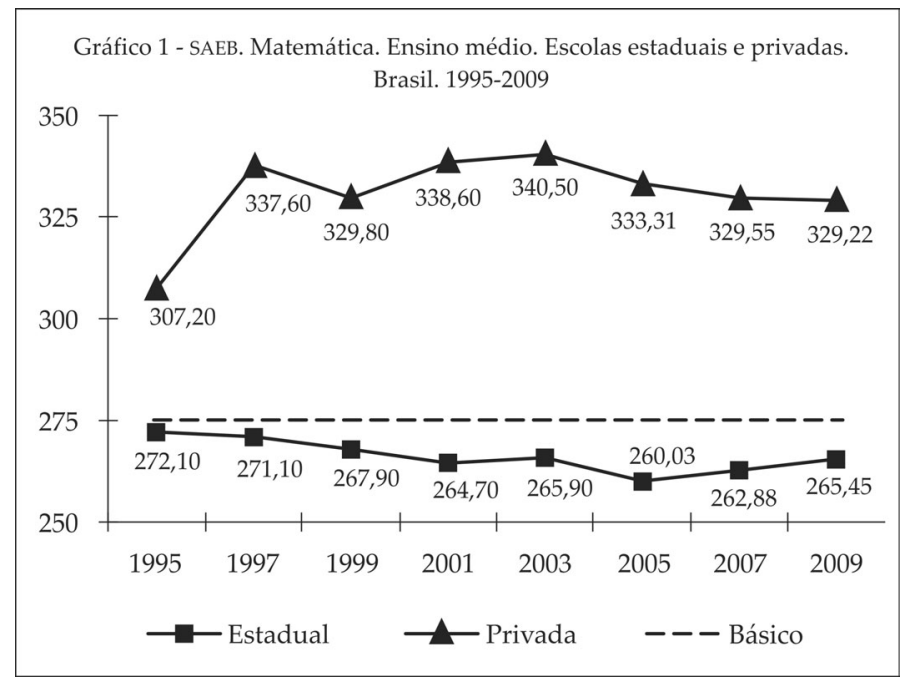

\section{Gráfico 2}

SAEB. Língua Portuguesa. Ensino médio - Escolas estaduais e privadas: Brasil (1995-2009)

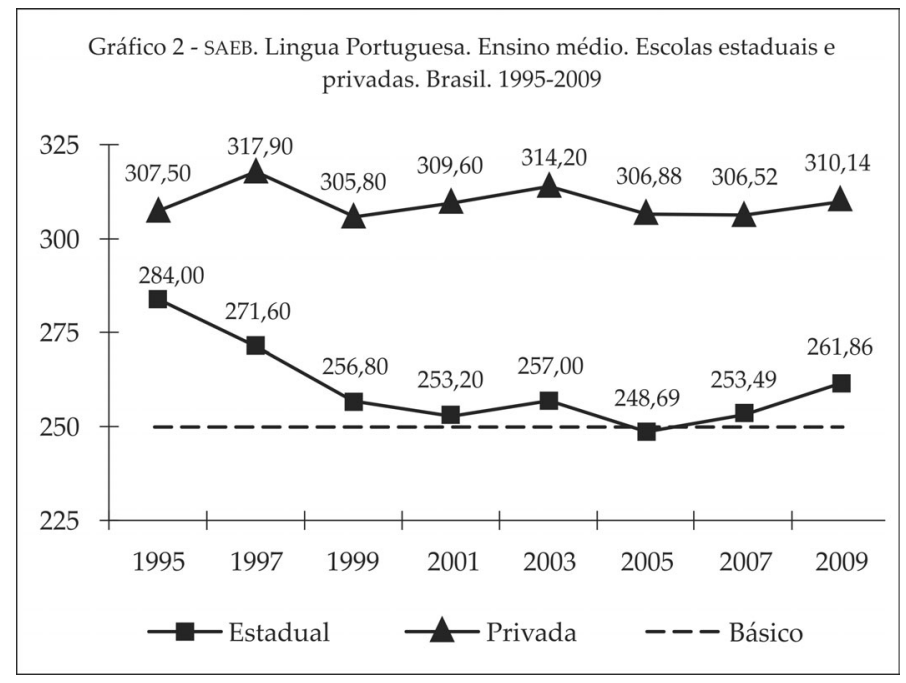

Não obstante, se a conceituação do que seria a qualidade da escola, na literatura e nas políticas educacionais, não obteve ainda um consenso, somos, contudo, crescentemente, testemunhas de inflexões importantes a respeito do lugar que as 
avaliações externas passaram a ocupar nas políticas educacionais, destacadamente no plano federal, situação nitidamente evidenciada por Fernandes e Gremaud (2007), os quais sinalizam com a necessidade de medidas de accountability - expressão inglesa traduzida mais comumente como responsabilização - para que houvesse incidência dos resultados dessas avaliações nas escolas.

É nesse terreno que o ENEM passa a ser a pedra de toque das avaliações externas para o ensino médio, diante do aparente pequeno impacto do sAEb. Contudo, como Sousa (1999), Sousa e Alavarse (2009) e Vianna (2003) ponderam, mesmo em momentos diferenciados, o ENEM não teria a propriedade de avaliar o ensino médio e nem mesmo a de ser indutor para alterações curriculares no conjunto do ensino médio brasileiro. Pode-se considerar, contudo, que o ENEM poderá assumir novo peso em relação ao ensino médio face aos seguintes aspectos: iniciativas de algumas universidades públicas em lançar mão do Exame como o único procedimento seletivo, substituindo completamente os clássicos exames vestibulares; sua aceitação, por parte de uma grande maioria de escolas privadas, como um crivo de mercado para disputar clientela; sua adoção, em 2009, como substituto ao Exame Nacional de Certificação de Competências na Educação de Jovens e Adultos (ENCCEJA), que permite a equivalência do ensino médio em função do desempenho nas provas; a utilização de seus resultados para concessão de bolsas na educação superior privada, pela via do Programa Universidade para Todos (PROUNI).

Retomando O IDEB, há uma questão controversa que reside na concepção de que este indicador expressaria a qualidade da escola ou da rede à qual se refere. Textualmente, no Decreto n. 6.094 de 2007, a formulação do IDEB apresenta uma visão extremamente objetivista sobre o seu potencial para indicar a qualidade da escola:

Art. 3 - A qualidade da educação básica será aferida, objetivamente, com base no IDEB, calculado e divulgado periodicamente pelo INEP, a partir dos dados sobre rendimento escolar, combinados com o desempenho dos alunos, constantes do censo escolar e do Sistema de Avaliação da Educação Básica - SAEB, composto pela Avaliação Nacional da Educação Básica - ANeb e a Avaliação Nacional do Rendimento Escolar (Prova Brasil).

Apesar das visões reducionistas de qualidade que o cercam, é possível considerar algumas potencialidades nо ІDEв por conta de duas características: por facilitar uma apreensão, mesmo que parcial, da realidade educacional brasileira e, sobretudo, por articular dois elementos que há muito tempo parecem ser antagônicos: o aumento da aprovação e o aumento do desempenho. Se qualidade não se confunde com desempenho em leitura e resolução de problemas, por outro lado, estes tópicos não são, de forma alguma, estranhos ao processo escolar que se pretenda de qualidade. Com efeito, o incremento do IDEB, a médio e a longo prazos, se dará pelo incremento desses dois fatores. 
Outra característica é dada pelo fato de o IDEB estar associado ao PDE e, em decorrência, ensejar o Plano de Ações Articuladas (PAR), que compreende várias iniciativas pactuadas entre a União e outros entes federados para a execução de programas com suporte técnico e financeiro, visando à melhoria dos indicadores educacionais, notadamente o próprio IDEB. Paralelamente ao PAR, foram desencadeadas ações do governo federal expressamente destinadas à educação. A este respeito, Saviani (2007, p. 1242), apesar de ponderar que não se trate exatamente de um plano, destaca que "a singularidade do pDE se manifesta naquilo que ele traz de novo, (...) da preocupação em atacar o problema qualitativo da educação básica brasileira". E, provavelmente, a grande medida, mesmo que formalmente anterior ao lançamento, se constitui no Fundo de Desenvolvimento da Educação Básica (FUNDEB).

Enquanto indicador, a questão consiste em dimensionar o seu potencial para contribuir no equacionamento e no enfrentamento de tarefas de planejamento educacional, uma vez que existem projeções do IDEB até 2021 para cada escola e rede, levando em conta, de alguma forma, as particularidades dessas unidades.

\section{Quadro 1}

IDEB e seus componentes. Escolas estaduais: Brasil (2005 a 2009)

\begin{tabular}{|l|c|c|c|}
\cline { 2 - 4 } \multicolumn{1}{c|}{} & $\mathbf{2 0 0 5}$ & $\mathbf{2 0 0 7}$ & $\mathbf{2 0 0 9}$ \\
\hline Ideb & 3,0 & 3,2 & 3,4 \\
\hline Nota & 4,06 & 4,18 & 4,34 \\
\hline Aprovação & $75 \%$ & $76 \%$ & $78 \%$ \\
\hline
\end{tabular}

Fonte: MEC/INEP.

\section{Quadro 2}

IDEB e seus componentes. Escolas privadas: Brasil (2005 a 2009)

\begin{tabular}{|l|c|c|c|}
\cline { 2 - 4 } \multicolumn{1}{c|}{} & $\mathbf{2 0 0 5}$ & $\mathbf{2 0 0 7}$ & $\mathbf{2 0 0 9}$ \\
\hline Ideb & 5,6 & 5,6 & 5,6 \\
\hline Nota & 5,96 & 5,90 & 5,96 \\
\hline Aprovação & $93 \%$ & $94 \%$ & $93 \%$ \\
\hline
\end{tabular}

Fonte: MEC/INEP.

Ao analisarmos os Quadros 1 e 2, que cotejam escolas estaduais e privadas, podemos perceber que, nas escolas privadas, antecipado pelas taxas de rendimento e pelos resultados dos dados do SAEB, não houve alteração de nenhum dos compo- 
nentes do IDEB, o que não deixa de chamar a atenção pela composição social desse segmento. Quanto às escolas estaduais, não houve a aprovação generalizada que alguns jornalistas chegaram a cogitar quando do lançamento do IDEB, pois esta seria uma estratégia fácil para aumentar o índice. Ocorreu, entre 2005 e 2009, um crescimento de $13,3 \%$ no IDEB, com uma variação de 3 pontos percentuais na taxa de aprovação e um ganho de 6,7\% na nota, relativa ao desempenho em matemática e língua portuguesa. Como salientado na análise dos resultados do SAEB, a variação maior foi em língua portuguesa (5,3\%) do que em matemática $(2,1 \%)$, dado que o IDEb resulta do produto da nota pela taxa de aprovação. Dimensionando o impacto de cada componente na variação do índice, tem-se, utilizando-se da padronização fornecida em Fernandes (2007), que a variação na aprovação contribui com 35\%, matemática com $18 \%$ e língua portuguesa com $47 \%$. Ou seja, apesar do quadro de precarização esboçado nas análises anteriores, considera-se como positivos esses ganhos na escola pública, os quais podem ser consequência de políticas de concentração de esforços nesta escola, embora demarquem as inúmeras tarefas ainda a cumprir para a efetiva democratização do ensino.

A questão seria, então, a vontade política de enfrentar efetivamente os desafios que o ensino médio impõe para amplas camadas, destacadamente aquelas que concernem à sua forma integrada, para a idade própria e para a EJA. Para isto o IDEB, isoladamente, não pode ser o indicador.

Seguramente, a conceituação e o dimensionamento da qualidade da educação escolar se constituem num complexo problema político e pedagógico, pois concentram leituras da sociedade, da escola e das relações que entre elas se estabelecem. Oliveira e Araújo (2005) demarcam o debate, apontando a necessidade de que os resultados de avaliações externas sejam incorporados sem que, contudo, se estabeleça determinismo nas relações entre eles e o trabalho dos professores, como se estes fossem os únicos e plenamente capazes de engendrar os resultados escolares. Outra posição, representativa de várias iniciativas no Brasil no sentido de responsabilização, quase que exclusiva, dos professores pelos resultados, é a defendida por Castro (2007, p. 61), para quem a qualidade da educação se expressa nos resultados de provas padronizadas e que, mesmo reconhecendo as precariedades na atividade docente, incluindo a sua remuneração, sustenta que a melhoria dos salários dos professores se daria pela "implantação de salários diferenciados mediante desempenho. Para isto, o ideal seria estabelecer sistemas de avaliação dos professores vinculados aos resultados das escolas". Em tal perspectiva, as avaliações externas, além da associação mecânica entre desempenho em provas e trabalho docente, desprezando frequentemente as condições das quais emergem esses resultados, confundem-se com um modelo de gerenciamento de recursos humanos, retirando-lhes todo o potencial pedagógico. 
Oliveira (2011, p. 137), apoiando-se em Nevo (1998), destaca que as avaliações externas parecem ter sido desenhadas muito mais para produzir informações para os gestores de redes educacionais "do que para ajudar os professores a analisarem os resultados, buscando rever seus métodos de ensino e práticas de avaliação". De acordo com a autora, "as comunicações de resultados das avaliações com foco na escola devem promover uma articulação com o trabalho pedagógico escolar de maneira a aprimorá-lo".

Como alerta Gimeno Sacristán (1998, p. 320), a existência de avaliações externas pode comprometer, pela ênfase na crença de seus resultados como portadores da "última palavra", os necessários debates críticos sobre a situação educacional e seus procedimentos, além de submeter os professores a uma pressão externa, "subtraindo-lhes a autonomia profissional" e impedindo-os, contraditoriamente, de desenvolver trabalho mais profícuo com seus alunos. Frente a isto, coloca-se como imperativo a busca de um processo mais amplo de avaliação de escolas e redes que, para além da utilização de provas padronizadas, tenha presente o caráter político da educação escolar. Reconhecer este caráter implica reconhecer profissionais e usuários das escolas como sujeitos que precisam ser considerados como tais nos processos avaliativos, pois, sem omitir-lhes as responsabilidades, são eles que, nos ambientes escolares, materializam a tarefa educativa.

Não se trata, portanto, de ignorar ou abandonar avaliações externas. Descartá-las nos impediria de ter acesso a informações que são relevantes e pertinentes aos desafios educacionais e que podem, inclusive, favorecer o seu equacionamento. Contudo, fazer delas o único procedimento para indicar a qualidade da escola e pautar iniciativas de políticas educacionais seria negar-se a enfrentar uma realidade que, por sua complexidade, demanda outros instrumentos e medidas, principalmente aqueles capazes de garantir as condições de existência do ensino médio, compreendido em suas dimensões de infraestrutura material e pedagógica.

\section{O Programa Nacional de Integração da Educação Profissional com a Edu- cação Básica na modalidade de Educação de Jovens e Adultos (PROEJA) ${ }^{1}$}

Resultado dos movimentos de resistência ao Decreto n. 2208, de 1997, e de reivindicações apresentadas por entidades representativas de educadores e do movimento popular ao Governo Lula, discutidas em seminários e conferências organizadas pelos ministérios da Educação e do Trabalho (Moraes, 2006; Franzói \& Machado, 2010), o PROEJA consiste, hoje, "por suas finalidades, fundamentos e diretrizes, na principal referência para a educação de jovens e adultos trabalhadores". ${ }^{2}$ Instituído pelo governo federal em 2005, por meio do Decreto n. 5.478, no âmbito da rede federal, o PROEjA tem em vista, inicialmente, ofertar cursos e programas de formação 
inicial e continuada de trabalhadores e/ou educação profissional técnica de nível médio de modo integrado ao ensino médio na modalidade de EJA. ${ }^{3}$

Em fevereiro de 2006, veio a público o primeiro Documento-Base do PROEJA, com o objetivo de apresentar fundamentos e orientações acerca da integração entre educação básica e educação profissional no nível médio. A referência explícita ao trabalho como princípio educativo, e à integração entre trabalho, ciência, tecnologia e cultura (MEC/SETEC, 2007, p. 35), expressa a intencionalidade de que o ensino médio integrado à educação profissional destinado ao público de EJA "deve materializar-se a partir da mesma concepção do Ensino Médio Integrado destinado aos adolescentes, embora as metodologias, o material didático e a organização espaçotemporal, entre outros elementos, sejam específicos para cada um desses grupos". Ou seja, de acordo com esse documento, no ensino médio integrado, para adolescentes ou para jovens e adultos, os conhecimentos "devem ser contemplados de forma equânime, em nível de importância e conteúdo, visando à formação integral do cidadão autônomo e emancipado" (Moura \& Pinheiro, 2009, p. 93).

Em julho do mesmo ano, o novo Decreto - n. 5.840 - ampliou a abrangência do PROEJA, com a inclusão da formação inicial e continuada de trabalhadores associada ao ensino fundamental também na modalidade EJA e acrescentando às instituições proponentes descritas no decreto anterior as "entidades privadas nacionais de serviço social, aprendizagem e formação profissional", ou seja, do Sistema "S". O projeto pedagógico integrado único é mencionado como obrigatório, mesmo quando os cursos envolverem "articulações interinstitucionais ou intergovernamentais". ${ }^{4}$ No ano seguinte, 2007, elaboraram-se novos Documentos-Base do PROEJA, o da formação inicial e continuada integrado ao ensino fundamental e o da educação profissional e tecnológica integrada à educação escolar indígena (MEC/SETEC, 2007c; 2007d). ${ }^{5}$

Tais medidas foram acompanhadas pela expansão e reordenamento da rede federal de educação profissional e tecnológica. No governo Lula, entre 2003 e 2010, foram construídas no Brasil 140 escolas técnicas novas, com investimento estimado de R \$ 1,1 bilhão. Hoje, a RFEPT conta com 354 unidades em todos os estados e no Distrito Federal. Quanto ao reordenamento, os Institutos Federais de Educação, Ciência e Tecnologia (IFECT) configuram-se como principais instituições da rede, definidas pela Lei n. 11.892/2008 como "autarquias de regime especial" (equiparadas às universidades federais no que diz respeito à autonomia), "instituições de educação superior, básica e profissional, pluricurriculares e multicampi, especializadas na oferta de educação profissional e tecnológica nas diferentes modalidades de ensino, com base na conjugação de conhecimentos técnicos, tecnológicos com as suas práticas pedagógicas". ${ }^{6}$ É importante observar que, embora não haja na lei impedimentos para a sua realização, a formação profissional integrada com o ensino 
fundamental na modalidade EJA, como o PROEJA FIC, não consta entre os objetivos dos Ifect. Complementarmente, o programa Brasil Profissionalizado, do Plano de Desenvolvimento da Educação (PDE), criado em 2007, repassou entre 2008 e 2010 recursos do governo federal para os estados, visando estimular a implementação do ensino médio integrado à educação profissional nas redes estaduais. Os recursos, da ordem de $\mathrm{R} \$ 1.508 .782 .427,58$, destinaram-se a obras de infraestrutura, desenvolvimento de gestão, práticas pedagógicas e formação de professores (MEC/SETEC, 2009; MEC, 2011).

Diferentemente de políticas ligadas à formação profissional ou à EJA, marcadas pela descontinuidade e pela focalização, o IFECT atribui-se, como metas, constituir-se em "política pública perene", com condições materiais adequadas e comprometimento de todos os envolvidos com o atendimento coerente do público-alvo, e tornar-se referência na oferta do ensino médio integrado à educação profissional na modalidade ejA (MEc/setec, 2007a; Rocha, 2011). Nessa direção, a Conferência Nacional de Educação Básica, realizada em 2008, ao identificar demandas da sociedade civil no âmbito das diferentes modalidades e etapas da educação básica, em consonância com a definição da EJA como um direito público subjetivo, ressaltou “a necessidade de consolidação de uma política de EJA, concretizada na garantia de formação integral, da alfabetização e das demais etapas de escolarização, ao longo da vida, inclusive àqueles em situação de privação de liberdade". Essa política,

\footnotetext{
(...) pautada pela inclusão e qualidade social, prevê um processo de gestão e financiamento que assegure isonomia de condições de EJA em relação às demais etapas e modalidades da educação básica, a implantação do sistema integrado de monitoramento e avaliação, uma política específica de formação permanente para o professor que atue nessa modalidade de ensino, maior alocação de percentual de recursos para estados e municípios e que esta modalidade de ensino seja ministrada por professores licenciados. (Parecer CNE/CEB n. 6/2010, p. 10-11)
}

Uma vez considerada a pertinência sócio-política e pedagógica do PROEJA, cabe verificar os procedimentos e critérios de avaliação diagnóstica propostos para viabilizar o monitoramento do Programa e a superação dos problemas surgidos em sua implementação, por meio de medidas governamentais e ações a serem desenvolvidas pelas instituições de ensino e da sociedade em geral.

\section{PROEJA - Educação profissional técnica de nível médio/ensino médio: ações e avaliações}

As dificuldades presentes na apreensão e análise do processo de implementação do PROEJA, derivadas em grande parte de lacunas de informação, encontramse amenizadas no caso do pRozja ensino médio, principalmente em virtude das 
diversas ações de fomento realizadas pelo MEC a programas de pós-graduação dedicados ao tema e à recente produção acadêmica daí derivada. Por outro lado, os dados levantados - muitas vezes incompletos - não fazem distinção, em sua maioria, entre as ações do PROEJA FIC e aquelas relacionadas ao PROEjA ensino médio. ${ }^{7}$

O Documento-Base proeja Ensino Médio (mec/setec 2007a, p. 57-64), além dos tópicos direcionados às práticas escolares de avaliação, destina um capítulo para os denominados "Aspectos Operacionais", no qual define que a coordenação geral do Programa caberá à SETEC, incumbida de "coordenar o processo de implantação, implementação e avaliação" do Programa e de organizar, "a seu critério (...) um núcleo gestor, a ser composto com representantes das Secretarias do MEC, da Fundação Coordenação de Aperfeiçoamento de Pessoal de Ensino Superior (CAPEs) e do Instituto Nacional de Estudos e Pesquisas Educacionais Anísio Teixeira (INEP)". Segundo o Documento, o acompanhamento e o controle social da implementação nacional do PROEjA seria "exercido por comitê nacional, com função consultiva" e "sua composição, as atribuições e o regimento do comitê definidos conjuntamente pelos Ministérios da Educação e do Trabalho e Emprego (Decreto n. 5.840/2006)". Não se encontrou, entretanto, nenhuma informação oficial posterior sobre a organização deste comitê nacional de avaliação.

Como gestora nacional do PROEJA, a SETEC assume a responsabilidade pelo estabelecimento de programas especiais para a formação de formadores e para pesquisa em educação de jovens e adultos, por meio da oferta de programas de especialização em educação de jovens e adultos, como modalidade de atendimento no ensino médio integrado à educação profissional; articulação institucional com vista a cursos de pós-graduação (mestrado e doutorado) que incidam em áreas afins do PROEJA; e fomento a linhas de pesquisa em educação de jovens e adultos, ensino médio e educação profissional. O monitoramento e a avaliação devem ser coordenados pela SETEC e incidem sobre: a) a aplicação dos recursos investidos; b) o projeto pedagógico e as instituições, utilizando, para tal, modelo similar ao Sistema Nacional de Avaliação do Ensino Superior (sINAEs); c) o pessoal envolvido no Programa, incluindo alunos. ${ }^{8}$

A consulta às informações disponibilizadas no sistema de comunicação e informação construído pelo MEC e acessíveis a pesquisadores e ao público em geral, permite visualizar, em parte, as condições atuais do Programa. O MEC apresenta dados sobre a cobertura do Programa em relação aos campi da RFEPT, as matrículas e a transferência de recursos para a sua implementação na rede federal e nos estados. ${ }^{9}$

Comparando-se os dados fornecidos pela SETEC e aqueles do INEP apresentados na Tabelas 7 e 4, é possível notar que entre 2006 e 2010 houve aumento tanto do número de matrículas, quanto do montante de recursos disponibilizados no período: em cinco anos, as matrículas cresceram oito vezes e os recursos transferidos, seis 
vezes..$^{10} \mathrm{Um}$ aspecto negativo a ser ressaltado é o do reduzido número de instituições que ofertam ações formativas no âmbito do PROEJA. Como observa Rocha (2011, p. 218), considerando o universo de 302 instituições da RFEPT habilitadas a desenvolver a oferta, apenas $64,9 \%$ (196) o fizeram em 2010, ou seja, estavam de acordo com a Lei n. 11.892/2008, a qual determina que o mínimo de $50 \%$ das vagas dos гғест sejam destinadas a ações formativas integradas (no ensino "regular" e na EJA). Assim, pelo menos (pois não se sabe ao certo quantos IFEct estão entre as 196 computadas em 2010), cerca de um terço dessas instituições não está oferecendo o PROEJA, ação considerada prioritária no rol de objetivos dos IFECT. Ao mesmo tempo, os repasses financeiros aos estados, nesse período, em vez de aumentarem, tendem a diminuir, sofrendo em 2010 um decréscimo de quase 50\% em relação ao ano de 2008.

\section{Tabela 7}

Número de instituições da RFEPT que desenvolvem ações do PROEJA e metas financeiras e físicas realizadas entre 2006 e 2010

\begin{tabular}{|ccccc|}
\hline Ano & $\begin{array}{c}\text { Instituições da RFEPT } \\
\text { que desenvolvem ações }\end{array}$ & $\begin{array}{c}\text { Meta financeira executada } \\
\text { (em milhões de R\$) }\end{array}$ & $\begin{array}{c}\text { Meta física executada } \\
\text { (em matrículas) }\end{array}$ \\
\hline 2006 & 58 & 6,0 & 4.000 \\
\hline 2007 & 66 & 23,2 & 9.747 \\
\hline 2008 & 123 & 20,2 & 14.939 \\
\hdashline 2009 & 116 & 35,9 & 19.533 \\
\hdashline 2010 & 196 & $37,0^{*}$ & 38.152 \\
\hline
\end{tabular}

Fonte: MEC/SETEC (2011d); MEC/simec (2011e).

*Valor previsto.

\section{Tabela 8}

Estados convenientes, escolas beneficiadas e metas financeiras realizadas no Programa Brasil Profissionalizado, em 2008 e 2009

\begin{tabular}{|c|c|c|c|}
\hline Ano & Estados convenentes & Escolas beneficiadas & $\begin{array}{c}\text { Meta financeira executada } \\
\text { (em R\$) }\end{array}$ \\
\hline 2008 & 19 & 46 & $525.152 .205,96$ \\
\hline 2009 & 23 & 83 & $225.675 .471,00$ \\
\hline \multirow[t]{2}{*}{2010} & 10 & 47 & $263.394 .260,46$ \\
\hline & & Total de recursos & $1.508 .782 .427,58$ \\
\hline
\end{tabular}

Fonte: Mec/setec (2011b; 2011c; 2011d); mec/simec (2011e). 
O fraco desempenho do PROEJA na RFEPT tem sido atribuído a diferentes problemas, considerados e analisados em estudos desenvolvidos, em número significativo, por educadores e pesquisadores participantes das ações previstas no Programa, tais como o PROEJA/CAPES/SETEC, e debatidos nos Diálogos PROEJA, "encontros microrregionais realizados pelas instituições federais, voltados para equipe técnica, docentes e estudantes dos cursos PROeJA" (MEC/SETEC, 2011c; 2011d). Em pesquisa que analisa o PROEJA EM e o PROEJA FIC, Rocha (2011) cita 23 destes estudos, nos quais são levantadas desde questões relacionadas aos procedimentos impositivos do MEC na implementação do Programa da RFEPT (Moura 2009, 2010; Costa 2009, 2010; Lopes 2009; Nascimento, 2009), ao despreparo do corpo docente para atuar com a proposta de currículo integrado e com o público da EJA, agravado pelo desconhecimento dos objetivos e estratégias do Programa (Moura 2009, 2010) e/ou a seus "preconceitos" em relação a esse público (Bonow, 2010), até dificuldades provenientes da "ausência de recursos materiais e humanos", da falta de professores, de infraestrutura e de material didático apropriado (Almeida, 2009; Hotz, 2010; Lopes, 2009).

As dificuldades de implementação, de acordo com alguns dos autores, estariam incidindo fortemente, "em conjunto com fatores inerentes à condição social que impedem a permanência do aluno na escola", para aumentar a evasão do público do proeja (Rocha, 2011, p. 124; Costa, 2010, p. 122). Os altos índices de evasão no PROEjA levaram a sETEC a desenvolver o "Projeto Inserção Contributiva", no sentido de "diagnosticar a situação dos cursos em algumas instituições federais" e "identificar as causas do alto índice de abandono dos cursos e estabelecer estratégias de monitoramento e avaliação para superação da evasão" (MEC/SETEC, 2011c; 2011d). Ao longo dos anos de 2007 e 2008, foram feitas visitas aos institutos e encaminhado formulário destinado à atualização e levantamento de informações gerais sobre: a instituição, o curso PROEJA (carga horária, área profissional, duração, nível) e sua coordenação, além de dados sobre os estudantes (etnia, gênero e faixa etária), número de matrículas, frequência, desistências etc. Tal pesquisa possibilitou, segundo a SETEC, obter "um panorama geral dos cursos PROEjA em desenvolvimento na Rede Federal" e a identificação das instituições com "alto índice de desistência dos cursistas". Segundo a SETEC, a consolidação dos dados revelou também, entre as causas da evasão nas escolas, "a ausência de transporte e alimentação adequados para o estudante". Nesse sentido, criou-se a Assistência ao Estudante PRoEJA, por meio da qual foram descentralizados $\mathrm{R} \$ 4.815 .700,00$ para a concessão de bolsas ( $\mathrm{R} \$ 100,00$ por estudante), com 9.120 estudantes atendidos em 2008 e 14.206 em 2009 (MEC/sETEC, 2011a; 2011b).

Para enfrentar as dificuldades apontadas desde o início do Programa em 2006, a SETEC, "no intuito de apoiar a promoção e a implementação de políticas sistemáticas de formação de docentes e gestores, de produção de conhecimento e de infraestrutura 
técnica para os campos educacionais envolvidos no PROEJA", incentivou as instituições federais a promoverem cursos de formação continuada de professores e gestores, de pós-graduação em nível de especialização, mestrado e doutorado, além de capacitações de curta duração, investindo mais de $\mathrm{R} \$ 43$ milhões nesses projetos (MEC/sETEC, 2011c). A Tabela 9 apresenta dados sobre essas atividades, que contaram com aproximadamente 17 mil matrículas (sendo que mais de um curso pode ser frequentado pela mesma pessoa).

\section{Tabela 9}

Tipo de formação continuada oferecida pelo MEC para corpo técnico-pedagógico da RFEPT, recursos executados, número de matriculados e informações complementares, no âmbito do PROEJA (2006 e 2009)

\begin{tabular}{|c|c|c|c|c|}
\hline Ano & $\begin{array}{l}\text { Tipo de formação } \\
\text { continuada }\end{array}$ & $\begin{array}{c}\text { Recurso } \\
\text { executado } \\
\text { (em R\$) }\end{array}$ & Matrículas & $\begin{array}{c}\text { Polos envolvidos/ } \\
\text { Projetos aprovados/ } \\
\text { Encontros realizados }\end{array}$ \\
\hline 2006 & Especialização & $3.734 .275,30$ & 1.400 & 15 polos \\
\hline \multirow{3}{*}{2007} & Capacitação & $3.661 .742,91$ & - & 24 projetos \\
\hline & Especialização & $10.624 .531,98$ & 3.450 & 21 polos \\
\hline & Mestrado e doutorado & $3.600 .000,00$ & - & 36 projetos \\
\hline \multirow{3}{*}{2008} & Capacitação & $4.886 .138,32$ & 6.431 & - \\
\hline & Especialização & $8.975 .288,19$ & 3.794 & 33 polos \\
\hline & Diálogos PROEJA & $427.944,71$ & - & 14 encontros \\
\hline 2009 & Especialização & $7.632 .802,12$ & 2.789 & 33 polos \\
\hline & Total & $43.542 .723,53$ & 17.864 & - \\
\hline
\end{tabular}

Fonte: Brasil, MEc/setec (2011c).

As informações propiciadas pela SETEC, por meio da montagem de seu "sistema de comunicação e informação", possibilitam dimensionar os esforços no sentido de monitorar o desempenho do programa, impulsionar e avaliar ações para o enfrentamento das diversas e variadas dificuldades surgidas no processo de sua implementação. Além do protagonismo na realização de estudos e pesquisas diagnósticas, cabe salientar a qualidade dos documentos construídos por equipes pertencentes às diferentes secretarias do MEC, em particular a SETEC e a Secretaria de Educação Continuada, Alfabetização e Diversidade (SECAD), ou em trabalho conjunto com outros ministérios e/ou educadores representantes de universidades, institutos federais, entidades científicas e sindicais - com o objetivo de viabilizar o debate conceitual, a explicitação de pressupostos teóricos e metodologias que informam os projetos 
formulados e orientam as ações previstas no Programa, nos seus diferentes campos - da gestão ao pedagógico. ${ }^{11}$

No entanto, o quadro disponível sugere que tais políticas, ainda que contribuam para minorar problemas, não têm produzido os resultados esperados na efetivação/garantia de direitos à população, tanto em termos de abrangência social quanto da concretização de sua proposta curricular diferenciada, de educação integrada, direcionada à construção da escola pública unitária. Nessas circunstâncias, tomando por base as considerações críticas e proposições apresentadas no documento coletivo "Políticas públicas de educação e trabalho na perspectiva dos direitos sociais" (IIEP, 2011), do qual são signatários vários educadores comprometidos com a educação de trabalhadores,$^{12}$ são apresentadas algumas questões centrais à consolidação do PROEJA como política pública.

Em primeiro lugar, cabe enfatizar que grande parcela dos problemas encontrados na implementação do PROEJA é proveniente do fato das várias ações ainda permanecerem como programas e não se constituírem em políticas de Estado; o que, do ponto de vista do financiamento, significa dizer que necessitam de indução por meio de repasses voluntários, por meio de convênio, ou se dão para além dos orçamentos ordinários. $\mathrm{O}$ fato de não serem compreendidas como ofertas regulares das redes e instituições de ensino coloca-as em situação de preterimento frente às demais ofertas educacionais Nessa condição, as medidas tendem a se efetivar de maneira descontinua e desarticulada entre si, não chegando a se constituir nem mesmo como políticas de governo. Permanece a necessidade de fontes de financiamento da educação integrada, tanto regular quanto na modalidade EJA..$^{13}$

Os elementos de diagnóstico levantados pela SETEC, pesquisadores e sujeitos participantes do processo evidenciam a necessidade da constituição de espaços de negociação social sobre diretrizes, institucionalização e operacionalização das ações do PRoEjA. A esse respeito, é oportuno mencionar como referencial o conceito de qualidade social da educação apresentado pelas novas Diretrizes Curriculares Nacionais do Ensino Médio (ainda não homologadas). No sentido designado, ainda que não sejam abandonados os instrumentos de avaliação dos resultados, a qualidade é vista com resultando de "movimentos de renovação pedagógica, movimentos sociais, de profissionais e por grupos políticos" e "associada às mobilizações pelo direito à educação, à exigência de participação e democratização e comprometida com a superação das desigualdades e injustiças"' (Brasil, 2011, p. 8). Como pondera Ferretti (2011, p. 2), "talvez por esta forma seja possível contribuir para que os inúmeros problemas relacionados ao ensino médio (...) sejam minorados, ou, quiçá resolvidos".

Com essa perspectiva, aponta-se outra dimensão política importante na configuração do PROEJA: o papel e as atribuições das instituições da RFEPT. O panora- 
ma observado induz a afirmar que para além de abrigar cursos dessa modalidade, a rede federal, beneficiada por sua expansão, detém o papel estratégico de viabilizar a oferta do PROEJA nos sistemas, de impulsionar e orientar as iniciativas estaduais e municipais, e tornar-se referência nacional para tal ação - equipamentos, instalações, formação continuada de professores, assessoria para implementação de currículos integrados, de itinerários formativos profissionais e de material didático -, bem como na realização dos processos de certificação. A consolidação da concepção sistêmica da educação, a ser concretizada por estados e municípios, que valoriza conjuntamente os níveis e modalidades educacionais, a partir da realização de políticas públicas universalizantes, deve ter como horizonte a completa integração do PROEJA ao Sistema Nacional de Educação. Para que isso possa se concretizar, torna-se necessário definir normativas que regulamentem a oferta de cursos de formação inicial e continuada integrada à escolarização. A ausência de um marco regulatório, de referenciais curriculares para a sua oferta, dificulta ou impede o delineamento de itinerários formativos tão necessários aos processos de reconhecimento de saberes e certificação profissional, assim como para concretização de currículos integrados no âmbito do PROEJA FIC. Se o PROEJA voltado para o ensino médio e educação profissional técnica de nível médio deve seguir as orientações do Catálogo Nacional de Cursos Técnicos de Nível Médio mantido pelo MEC (Resolução n. 3, de 9 de julho de 2008), o mesmo não ocorre com o PROEJA FIC, pois os cursos de formação profissional inicial não estão submetidos à regulamentação e, no máximo, para efeito de titulação, adequam-se às orientações da Classificação Brasileira de Ocupações, referência oficial para o desenvolvimento dos projetos de formação e certificação pela Rede Nacional de Certificação e Formação Inicial e Continuada (CERTIFIC) (Portaria Ministerial n. 1087, de 20 de novembro de 2009), instrumento inadequado para orientar processos formativos. E, como enfatiza o documento coletivo referenciado, é preciso avançar também na elaboração de um Guia Nacional de Formações e Certificações Profissionais, de modo a estabelecer parâmetros comuns com vistas à coordenação nacional das ações para tal fim.

Observa-se, de fato, poucos avanços na articulação entre educação básica e formação profissional, tanto no ensino médio para a "idade adequada" quanto na modalidade EJA. A fala dos sujeitos participantes indica a existência de dificuldades no desenvolvimento de currículos em várias escolas federais que retomaram a oferta de cursos técnicos integrados ao ensino médio, havendo ainda indefinições na implantação dos eixos tecnológicos, metodologia adotada nos Catálogos Nacionais dos Cursos Técnicos e dos Cursos Superiores de Tecnologia. As medidas a serem tomadas exigem, por um lado, eficaz coordenação entre as políticas Econômica, de Desenvolvimento, de Trabalho e Renda e de Educação, que lhes possibilite considerar a diversidade de públicos a serem atendidos - trabalhadores urbanos, trabalhadores no campo, indígenas, quilombolas, além de pessoas com deficiências. 
Por outro lado, é preciso enfrentar embates políticos na reformulação da própria Lei das Diretrizes Bases da Educação Nacional e das Diretrizes/Parâmetros Curriculares Nacionais do Ensino Técnico de Nível Médio, na defesa do ensino médio integrado tanto para a idade própria, como em suas diferentes modalidades. A proposta de ensino médio integrado é incompatível com a abordagem da formação por competências, no que se refere à concepção teórica/política da relação entre trabalho e educação e à concretização de sua forma pedagógica na relação entre educação básica e educação profissional. $\mathrm{O}$ aparecimento de projetos claramente identificados com interesses de grupos empresariais específicos expressa o recrudescimento da disputa política no âmbito governamental. É o caso do atual Programa Nacional de Acesso ao Ensino Técnico e Emprego (pronatec) (Projeto de Lei em discussão no Congresso Nacional), que apresenta elementos privatizantes, propõe a adequação funcional do aluno ao mercado e induz os estados a atuarem no ensino médio concomitante à educação profissional, em "parceria" com o Sistema "S", com bolsas financiadas aos alunos pelo governo federal, por meio de nova linha de crédito do Banco Nacional de Desenvolvimento Econômico e Social (BNDES). ${ }^{14}$ De acordo com esse programa, expandir a oferta de financiamento estudantil à educação profissional técnica de nível médio significa promover a compra de vagas em instituições privadas. O próximo passo seria o voucher (vales educacionais) para que o público da educação básica pública estude em escolas privadas..$^{13} E$ É necessário avaliar criticamente a proposta e reforçar a estratégia que vimos defendendo do fortalecimento da escola pública - para que venha a ter plenas condições de implementar o ensino médio integrado à educação profissional, para a idade adequada e nas modalidades PROEJA e PROEJA FIC, na perspectiva da educação politécnica e igualitária, por meio da ampliação significativa de recursos públicos para sua implementação.

\section{Considerações finais}

Neste artigo, procura-se salientar que a avaliação do ensino médio brasileiro comporta elementos que ultrapassam o modo pelo qual, recentemente, tem se colocado o debate. A tônica da qualidade associada ao desempenho dos alunos em avaliações externas em larga escala revela-se insuficiente, ainda que em muitos aspectos seja pertinente e deva ser levada em conta. Além das limitações relativas aos objetos dessas avaliações e aos seus instrumentos - provas com itens de múltipla escolha -, a insuficiência reside em querer derivar a qualidade da escola exclusivamente do desempenho de seus alunos. A apreensão da qualidade do ensino médio, questão candente para as políticas públicas, deve, necessariamente, abarcar outros aspectos, como se procurou alinhavar.

A qualidade do ensino médio concentra enormes desafios às políticas educacionais, pois ainda são necessárias medidas para a expansão de suas matrículas, 
tanto para aqueles considerados em idade adequada, quanto para os amplos contingentes que constituem o público potencial da educação de jovens e adultos. Nestes termos, o ensino médio ainda é uma etapa educacional para poucos no Brasil, configurando um quadro de negação de direitos, como revelam os dados apresentados. São necessárias iniciativas para garantir a permanência e o sucesso escolar dos que se matriculam, fatores que ainda não fazem parte da realidade do ensino médio, haja vista a situação de um fluxo extremamente restritivo com elevados percentuais de reprovação e abandono, resultando em taxas reduzidas de concluintes, que ainda se encontram, na média, com baixa proficiência, de acordo com os resultados do SAEB.

Contudo, a partir das considerações sobre o ensino médio integrado à educação profissional, avança-se para outro terreno, indicando que a incorporação do trabalho como princípio educativo pode se constituir em elemento estratégico que dote o ensino médio, tanto para aqueles em idade adequada como para os de EJA, da qualidade necessária a uma formação de base que integre trabalho, ciência e cultura. O trabalho como princípio educativo da integração curricular pode garantir unidade a essa etapa, tradicionalmente apresentada como cindida entre características propedêuticas e preparação para o trabalho.

Com essa perspectiva, espera-se que o Plano Nacional da Educação 2011-2020 venha a consolidar medidas capazes de promover a universalização do ensino médio com qualidade teórica, técnica e política. Isso significa propiciar as bases jurídicas para a execução de metas e estratégias que estabeleçam como prioridade a oferta pública do ensino médio, em suas diferentes modalidades e na forma integrada. É preciso, sobretudo, que o atual governo realize, com a participação da sociedade, projeto estratégico de enfrentamento da situação dos milhares de jovens e adultos que não tiveram acesso à educação básica e à formação profissional, sob uma referência de política de Estado. Na direção apontada pelo documento coletivo (IIEP, 2011), considera-se que, do ponto de vista político, econômico e social, as condições estão maduras para o seu desenvolvimento e que o atual governo, a terceira gestão do Partido dos Trabalhadores, não pode adiar mais a sua implementação.

\section{Notas}

1. Agradecemos a Caetana Juracy Rezende Silva, do MEc/setec, e a Sebastião Lopes Neto, do IIEP, pelas valiosas informações/sugestões relativas ao PROEJA.

2. A esse respeito, consultar o Documento Coletivo "Políticas públicas de educação e trabalho na perspectiva dos direitos sociais", resultado de Oficina Educação e Trabalho, organizada pelo GT de Educação e Trabalho, da Faculdade de Educação da usp e pelo Intercâmbio, Informações, Estudos e Pesquisas (IIEP), nos dias 10, 11 e 12 de dezembro de 2010, encaminhado ao MEc/setec. Utiliza-se aqui a versão publicada pelo IIEP (2011). 
3. O proeja foi formulado após o Decreto n. 5.154 de 2004, que substituiu o Decreto n. 2.208 de 1997, e manteve o ensino concomitante e o subsequente, mas reintroduziu a alternativa da formação integrada, no qual os alunos voltaram a ter uma única matrícula na educação técnica de nível médio.

4. A Lei n. 11.741, de 16 de julho de 2008, altera os dispositivos da Lei de Diretrizes e Bases da Educação Nacional, Lei n. 9.394/1996, para institucionalizar e integrar as ações da educação técnica de nível médio, da educação de jovens e adultos e da educação profissional e tecnológica.

5. O PROEJA Indígena pode ser efetivado tanto em nível de integração de ensino médio com educação profissional técnica de nível médio, quanto de integração de ensino fundamental com formação inicial. Entre as instituições que operam nesse âmbito encontram-se o Instituto Federal Norte de Minas - Campus Januária, que atendeu o povo Xakriabá com ensino fundamental e formação inicial na área de agropecuária; e a ufrgs que desenvolve, de dezembro de 2010 a junho de 2012, o curso de "Especialização pRoEjA Indígena", com 360 horas. Sobre isso, ver Rocha (2011).

6. A Lei n. 11.892, de 29 de dezembro de 2008, institui a Rede Federal de Educação Profissional, Científica e Tecnológica (RFEPT) e cria os Institutos Federais de Educação, Ciência e Tecnologia. Na atualidade, a RFEPT possui 354 unidades em todos os estados e no Distrito Federal e configura-se da seguinte maneira: 36 IFECT com seus 302 campi; 2 CEFET (MG e RJ) com 9 e 7 campi, respectivamente; 25 escolas técnicas vinculadas a universidades; e 1 Universidade Tecnológica Federal (PR) com seus 11 campi.

7. A esse respeito, consultar a tese de doutorado de Rocha (2011).

8. Com o objetivo de dar transparência e facilitar o monitoramento, controle e avaliação do Programa, considerou-se indispensável instituir um sistema eletrônico de registro e gerenciamento acadêmico (sIGA), interligado ao Sistema de Informações da Educação Profissional (SIEP). As informações cadastradas no sistema podem ser acessadas por meio de senhas disponibilizadas aos responsáveis pelo Programa nas instituições proponentes. Para dar visibilidade ao Programa, além de um link específico do MEC, a SETEC assume a responsabilidade de viabilizar ambiente virtual e colaborativo de aprendizagem que sirva de suporte à mediação pedagógica e de gestão para as instituições participantes (chat, fórum, lista de discussão) (MEC/setec, 2007a).

9. As tabelas 7, 8 e 9 foram elaboradas por Rocha (2011, p. 215, 216, 219), a partir dos dados divulgados em documentos oficiais da SETEC.

10. Como já foi indicado, em 2010, a RFEPT foi superada pela primeira vez, em número de matrículas, pelas redes estaduais de ensino, na oferta do ensino médio integrado na modalidade EJA. No caso das matrículas do PROEJA FIC, conforme dados fornecidos pelo MEC/INEP, em 2009, a RFEPT contribuiu com os menores índices na oferta do ensino fundamental integrado na modalidade EJA (55 matrículas), prevalecendo a oferta das redes estaduais (1.599) e municipais (1.766) - números bastante reduzidos quando comparado com a oferta do PROEJA médio integrado.

11. Entre eles estão os três documentos-base que fundamentam o PROEJa (2006-2007); o texto "Institutos Federais. Lei n. 11.892, de 29 de dezembro de 2008. Comentários e Reflexão", de 2009, elaborado pela SETEC em colaboração com o Instituto Federal Fluminense; e ainda o estudo "Diretrizes Curriculares Nacionais para a Educação Profissional Técnica de Nível Médio em debate", desenvolvido a partir de quatro encontros presenciais em Brasília, em julho e agosto de 2010, por Grupo de Trabalho socialmente representativo, organizado pela SETEC.

12. A esse respeito, consultar o Documento Coletivo (IIEP, 2011). As matriculas PROEJA técnico/médio da rede federal têm recurso garantido pela matriz orçamentária das instituições. O orçamento foi ampliado significativamente esse ano, com a incorporação dos recursos da assistência estudantil (para proeja e estudantes de baixa renda, em geral). As matrículas proeja Fic da rede federal também têm recurso de manutenção pelo orçamento ordinário, independente de estarem vinculadas ao ensino ou à extensão. As matrículas PROEJA técnico/médio, somente na forma de oferta integrada (não alcança a forma concomitante), nas redes estaduais, têm financiamento de manutenção pelo FUNDEB.

13. Apesar da dívida de mais de $\mathrm{R} \$ 3$ bilhões do Sistema S para com a União, o Pronatec prevê, de acordo com matéria publicada no jornal Valor Econômico de 21 de fevereiro de 2011, uma linha de crédito do BNDES para ampliar/modernizar a rede estimada em mais de $\mathrm{R} \$ 15$ bilhões. A garantia

Educ. Soc., Campinas, v. 32, n. 116, p. 807-838, jul.-set. 2011 
dos empréstimos será composta pela antecipação das receitas das entidades do Sistema S, que fecharam 2010 com arrecadação acima dos $\mathrm{R} \$ 10$ bilhões (que constitui fundo público, na medida em que os recursos são originários de contribuição social, com base no desconto de $2,5 \%$ sobre a folha de pagamentos das empresas, embutidos no custo das mercadorias e repassados aos consumidores).

14. Segundo a proposta, o governo, ao invés de fornecer diretamente a educação para todos, forneceria vales para as famílias, que poderiam usá-los para comprar vagas nas escolas públicas ou privadas que escolhessem. O caso do Chile, país em que o sistema de vouchers foi introduzido em 1981, como parte das reformas liberais de Pinochet, mostra que o sistema pode ter consequências perversas. A esse respeito, consultar Cosse (2003).

\section{Referências}

ALMEIDA, A. Um estudo do e no processo de implantação no estado do Paraná do PROEJA: problematizando as causas da evasão. 2009. 114f. Dissertação (Mestrado em Educação) - Setor de Educação, Universidade Federal do Paraná, Curitiba.

BONAMINO, A.; FRANCO, C. Avaliação e política educacional: o processo de institucionalização do sАeв. Cadernos de Pesquisa, São Paulo, n. 108, p. 101-132, nov. 1999.

BONOW, D. A exclusão escolar no PROEJA IF sul-rio-grandense: representações de estudantes evadidos. 2010. 201f. Dissertação (Mestrado em Educação) - Faculdade de Educação, Universidade Federal de Pelotas, Pelotas.

BRASIL. Decreto n. 5.840, de 13 de julho de 2006. Institui, no âmbito federal, o Programa Nacional de Integração da Educação Profissional com a Educação Básica na Modalidade de Educação de Jovens e Adultos - PROEJA, e dá outras providências. Diário Oficial da União, Brasília, DF, 14 jul. 2006.

BRASIL. Decreto n. 6.094, de 24 de abril de 2007. Dispõe sobre a implementação do Plano de Metas Compromisso Todos pela Educação, pela União Federal, em regime de colaboração com Municípios, Distrito Federal e Estados, e a participação das famílias e da comunidade, mediante programas e ações de assistência técnica e financeira, visando a mobilização social pela melhoria da qualidade da educação básica. Diário Oficial da União, Brasília, DF, 25 abr. 2007.

BRASIL. Lei n. 11.741, de 16 de julho de 2008. Altera dispositivos da Lei n. 9.394, de 20 de dezembro de 1996, que estabelece as diretrizes e bases da educação nacional, para redimensionar, institucionalizar e integrar as ações da educação profissional técnica de nível médio, da educação de jovens e adultos e da educação profissional e tecnológica. Diário Oficial da União, Brasília, DF, 17 jul. 2008.

BRASIL. Ministério da Educação. Brasil profissionalizado: apresentação. Disponível em: <http://portal.mec.gov.br>. Acesso em: 1ํo jul. 2011. 
BRASIL. Ministério da Educação. SIMEC - módulo público: painel de controle do MEc. Disponível em: <http://painel.mec.gov.br>. Acesso em: 23 jun. 2011e.

BRASIL. Ministério da Educação. Conselho Nacional de Educação. Câmara de Educação Básica. Parecer CNE/CEB n. 6/2010, aprovado em 7 de abril de 2010. Reexame do Parecer CNE/CEB n. 23/2008, que institui Diretrizes Operacionais para a Educação de Jovens e Adultos - EJA. Brasília, DF: MEC, 2010.

BRASIL. Ministério da Educação. Secretaria de Educação Profissional e Tecnológica. Programa de Integração da Educação Profissional Técnica de Nível Médio ao Ensino Médio na modalidade de Educação de Jovens e Adultos: documento base. Brasília, DF: MEC, 2006. 59p.

BRASIL. Ministério da Educação. Secretaria de Educação Profissional e Tecnológica. Programa Nacional de Integração da Educação Profissional com a Educação Básica na Modalidade de Educação de Jovens e Adultos - PRoeja: Educação Profissional Técnica de Nível Médio/Ensino Médio; documento base. Brasília, DF: MEC, 2007a. 71p.

BRASIL. Ministério da Educação. Secretaria de Educação Profissional e Tecnológica. Programa Nacional de Integração da Educação Profissional com a Educação Básica na Modalidade de Educação de Jovens e Adultos - PROEJA: formação inicial e continuada/ensino fundamental: documento base. Brasília, DF: MEC, 2007b. 79p.

BRASIL. Ministério da Educação. Secretaria de Educação Profissional e Tecnológica. Programa Nacional de Integração da Educação Profissional com a Educação Básica na Modalidade de Educação de Jovens e Adultos - PROEjA: Educação Profissional e Tecnológica Integrada à Educação Escolar Indígena: documento base. Brasília, DF: MEC, 2007c. 123p.

BRASIL. Ministério da Educação. Secretaria de Educação Profissional e Tecnológica. Relatório de gestão: exercício 2008. Disponível em: <http://portal.mec.gov.br >. Acesso em: 25 maio 2011a.

BRASIL. Ministério da Educação. Secretaria de Educação Profissional e Tecnológica. Tomada e prestação de contas anual: Relatório de gestão 2009. Disponível em: <http:// portal.mec.gov.br>. Acesso em: 25 maio 2011b.

BRASIL. Ministério da Educação. Secretaria de Educação Profissional e Tecnológica. PROEJA: apresentação. 2010. Disponível em: <http://portal.mec.gov.br>. Acesso em: 25 maio 2011c.

BRASIL. Ministério da Educação. Secretaria de Educação Profissional e Tecnológica. Sinopses das ações PROEJA, 2006 a 2009. Disponível em: <http://portal.mec.gov.br>. Acesso em: 15 junho 2011d. 
CASTRO, M.H.G. O desafio da qualidade. In: Ituassu, A.; Almeida, R. (Org.). O Brasil tem jeito?. v. 2: educação, saúde, justiça e segurança. Rio de Janeiro: Zahar, 2007. p. 35-72.

COSSE, G. Voucher educacional: nova e discutível panacéia para a America Latina. Cadernos de Pesquisa, São Paulo, n. 118, p. 207-246, mar. 2003.

COSTA, M.A. Formas estruturantes da organização curricular e a materialização do PRoejA no Curso Técnico de Mecânica do CEFET-MG. 2010. 140p. Dissertação (Mestrado em Educação Tecnológica) - Centro Federal de Educação Tecnológica de Minas Gerais, Belo Horizonte.

COSTA, R.C.D. O pRoeja para além da retórica: um estudo de caso sobre a trajetória de implantação do programa no Campus Charqueadas. 2009. 108p. Dissertação (Mestrado em Educação) - Faculdade de Educação, Universidade Federal do Rio Grande do Sul, Porto Alegre.

FERNANDES, R. Índice de Desenvolvimento da Educação Básica (IDEB). Brasília, DF: INEP, 2007. 26p. (Série Documental. Textos para Discussão, 26).

FERNANDES, R.; GREMAUD, A.P. Qualidade da educação: avaliação, indicadores e metas. In: Veloso, F. et al. (Org.). Educação básica no Brasil: construindo o país do futuro. Rio de Janeiro: Elsevier, 2009. p. 213-238.

FERRETTI, C. Questões relativas ao ensino médio: texto elaborado como subsídio à Audiência Pública sobre Ensino Médio (Senado Federal). São Paulo, 2011. (mimeo.).

FÓRUM Estadual de Educação de Jovens e Adultos - SP. Representação com pedido de instauração de Inquérito Civil Público e propositura de medida judicial. São Paulo, 30 set. 2010.

FRANZÓI, N.L.; MACHADO, M.M. Apresentação: trajetória de educação e trabalho na vida de jovens e adultos. Educação \& Realidade, Porto Alegre, v. 35, n. 1, p. 11-17, jan./abr. 2010.

GIMENO SACRISTÁN, J. A avaliação no ensino. In: Gimeno SACristán, J.; Pérez Gómez, A.I. Compreender e transformar o ensino. 4. ed. Trad. de Ernani F. da Fonseca Rosa. Porto Alegre: ARTMED, 1998. p. 295-351. (Original de 1996).

HADDAD, F. O Plano de Desenvolvimento da Educação: razões, princípios e programas. Brasília, DF: INEP, 2008. 23p. (Série Documental. Textos para Discussão, 30).

HOTZ, K.G. Avaliação da implementação do PRoeja em municípios do Oeste do Paraná (2008-2009). 2010. 263f. Dissertação (Mestrado em Educação) - Centro de Educação, Comunicação e Artes, Universidade Estadual do Este do Paraná, Cascavel. 
INSTITUTO BRASILEIRO DE GEOGRAFIA E ESTATÍSTICA (IBGE). Coordenação de População e Indicadores Sociais. Síntese de indicadores sociais: uma análise das condições de vida da população brasileira. Rio de Janeiro: IBGE, 2010. 321p. (Estudos e Pesquisas. Informação Demográfica e Socioeconômica, n. 27).

INTERCÂMBIO, INFORMAÇÕES, ESTUDOS E PESQUISAS (IIEP). Políticas públicas de educação e trabalho na perspectiva dos direitos sociais. São Paulo: IIEP, 2011. 42p.

LOPES, J. Educação profissional integrada com a educação básica: o caso do currículo integrado do PRoEja. 2009. 191f. Dissertação (Mestrado em Educação Tecnológica) - Centro Federal de Educação Tecnológica de Minas Gerais, Belo Horizonte.

MORAES, C.S.V. Educação permanente: direito de cidadania, responsabilidade do Estado. Trabalho, Educação \& Saúde, Rio de Janeiro, v. 4, n. 2, p. 395-416, 2006.

MOURA, D.H. Educação geral e formação profissional: política pública em construção. In: Regattieri, M.; Castro. J.M. (Org.). Ensino médio e educação profissional: desafios de integração. Brasília, DF: UnESCO, 2009. p. 119-136.

MOURA, D.H. A implantação do Proeja no CEFET RN: avanços e retrocessos. Disponível em: <http:www2.ifrn.edu.br>. Acesso em: 2010.

MOURA, D.H.; PINHEIRO, R.A. Currículo e formação humana no ensino médio integrado de jovens e adultos. Em Aberto, Brasília, DF, v. 22, n. 82, p. 91-108, 2009.

NASCIMENTO, M. Práticas administrativas e pedagógicas desenvolvidas na implementação do PROEJa na eAJAFT: discurso e realidade. 2009. 157f. Dissertação (Mestrado em Educação) - Faculdade de Educação, Universidade de Brasília, Brasília.

NEVO, D. Avaliação por diálogos: uma contribuição possível para o aprimoramento escolar. In: SEMINÁRIO INTERNACIONAL DE AVALIAÇÃO EDUCACIONAL, 1997, Rio de Janeiro. Anais... Brasília, DF: INEP, 1998. p. 89-97.

OLIVEIRA, A.P.M. A Prova Brasil como política de regulação da rede pública do Distrito Federal. 2011. 276f. Dissertação (Mestrado em Educação) - Programa de Pós-Graduação em Educação, Universidade de Brasília, Brasília.

OLIVEIRA, R.P.; ARAUJO, G.C. Qualidade do ensino: uma nova dimensão da luta pelo direito à educação. Revista Brasileira de Educação, São Paulo, n. 28, p. 5-23, jan./abr. 2005.

ROCHA, J.M. Formação inicial de trabalhadores e elevação de escolaridade: políticas públicas de qualificação profissional (1963-2011). 2011. 277p. Tese (Doutorado em Educação) - Faculdade de Educação, Universidade de São Paulo, São Paulo.

SAVIANI, D. O Plano de Desenvolvimento da Educação: análise do projeto do MEc. Educação \& Sociedade, Campinas, v. 28, n. 100, p. 1231-1255, out. 2007. 
SOUSA, S.M.Z.L. A que veio o ENEm? Revista de Educação AEC, Brasília, DF, v. 28, n. 113, p. 53-60, out./dez. 1999.

SOUSA, S.M.Z.L.; ALAVARSE, O.M. O "novo ENEM" democratiza o acesso ao ensino superior e induz melhorias no ensino médio?: não: quem se beneficia dessas alterações? Folha de S. Paulo, São Paulo, p. A3, 23 maio 2009.

SOUSA, S.M.Z.L.; OLIVEIRA, R.P. Sistemas estaduais de avaliação: uso dos resultados, implicações e tendências. Cadernos de Pesquisa, São Paulo, v. 40, n. 141, p. 793822, set./dez. 2010.

VIANNA, H.M. Avaliações em debate: SAeb, enem, Provão. Brasília, DF: Plano, 2003.

WEBER, S. Relações entre esferas governamentais na educação e PDE: o que muda? Cadernos de Pesquisa, São Paulo, v. 38, n. 134, p. 305-318, maio/ago. 2008.

Recebido em 20 de julho de 2011.

Aprovado em 3 de agosto de 2011. 